\title{
Status of Wendelstein 7-X Construction
}

\author{
F. Schauer for the W7-X team
}

Max-Planck Institut für Plasmaphysik, Branch Institute Greifswald, Euratom Association, D-17491 Greifswald, Germany

\begin{abstract}
Wendelstein 7-X (W7-X) is a fully optimised low-shear stellarator and shall demonstrate the reactor potential of a HELIAS-type fusion device. It is presently under construction at the Max-Planck-Institute for Plasmaphysics (IPP), Greifswald site. The superconducting magnet system enables continuous operation, limited only by the plasma exhaust cooling water system whose capacity is designed for 30 minutes full power operation. Companies spread all over Europe participate in the manufacture of this large and complex machine. Whereas most of the component production progresses well, the coil delivery has been hampered over the years by a variety of problems. Another cause of concern was the mechanical structure which - with the progressing of in-depth analyses - turned out to be increasingly complex. As of now the situation has widely stabilized, and component manufacture and assembly is making reasonable progress.
\end{abstract}

Keywords: Wendelstein 7-X, W7-X, fusion, stellarator, superconducting magnet 


\section{Introduction}

Wendelstein 7-X (W7-X) is a HELIAS-type stellarator which is optimized with regard to physics and engineering criteria [1]. It is presently under construction at the Greifswald branch of the Max-Planck-Institute for Plasma Physics (IPP),. The magnetic field configuration has a five-fold symmetry with helical axis and low shear, the rotational transform at the plasma boundary is close to unity. Five identical modules build up the machine, each one with flip-symmetry of both half-modules (HM). Major radius is $5.5 \mathrm{~m}$ and the averaged minor plasma radius is $0.55 \mathrm{~m}$. Main goal as a step on the road to a HELIAS type stellarator fusion power plant is to prove the predicted properties, and to demonstrate steady state operation.

The W7-X magnet is composed of 50 non-planar and 20 planar superconducting coils (NPC, PLC and sc, resp.). Main coil components are the winding pack (WP) made up of a cable-in-conduit conductor with electrical insulation, and the massive steel housing. Each of the ten half-modules contains five NPCs and two PLCs of different geometries. The ten coils of one type are connected in series by a sc busbar, giving seven groups. Each group is supplied by an individually adjustable power supply via water-cooled Al-busbars and one pair of current leads. The NPCs produce the main stellarator field, whereas the PLCs enhance the experimental flexibility by allowing to vary the field configuration.

Integral part of the magnet is the cold mechanical structure which supports the weight and, jointly with the coil casings, the enormous electromagnetic (EM) forces. Welded, bolted and gliding structure elements are placed between the coils, and bolted flange connections transfer the magnetic and weight forces to a ring-shaped central support structure (CSS). The latter rests on ten pillars ("cryolegs") whose bottom ends are at ambient temperature.

The magnet system is contained within an evacuated cryostat whose wall insides are covered with heat-reflecting multilayer insulation and an actively He-cooled thermal shield. The cryostat walls consist of the plasma vessel (PV), the outer vessel $(\mathrm{OV})$, and the ports which connect the outside environment - through the cryostat space - to the PV. 
The components inside the PV ("in-vessel components", IVC) comprise divertor target plates and baffles for energy and particle control, panels and heat shields for wall protection, control coils to modify the magnetic field, cryo-pumps, and finally the corresponding water, $\mathrm{LN}_{2}$ and supercritical He coolant supply lines.

Besides these aforementioned basic machine components a number of peripheral and auxiliary equipment is necessary for operation, like plasma heating systems (ECRH, ICRH and NBI), cooling water supply for the IVCs, the PV as well as port walls, the refrigeration system, the instrumentation, the gas and electricity supplies, etc. The ECRH installation is in a quite advanced status already: Four out of the ten $140 \mathrm{GHz}, 1 \mathrm{MW}$ gyrotrons are delivered, and the transmission lines are finished up to the torus hall. Concerning diagnostics including data acquisition and processing, at this stage of W7-X construction the main emphasis is laid on the development of a set of "start-up diagnostics".

Fig.1 shows a CAD drawing of the basic machine which will be described below in more detail. The peripheral components will not be further discussed within this paper, part of them are presented elsewhere at this conference [2-6].

Detail design and manufacturing of components have considerably progressed. In the last years, new finite element (FE) models of the magnet system and cryostat for global and detailed analyses have been generated [7]. Mounting tools and technologies were developed, and the actual assembly of the stellarator has started. The development of diagnostics as well as heating and control systems is progressing well. However, also a number of quality problems, in particular concerning the NPC electrical insulation, were discovered which necessitated some detail design changes and repairs [8]. In addition, the comprehensive mechanical FE analyses (FEA) revealed at some points the need for structure reinforcements and modifications. All these circumstances have caused a significant delay of the project. As a reaction to the problems the project was reorganized and the personnel significantly upgraded. 


\section{Basic device components}

Main components of the W-7X basic device are the magnet system, the cryostat, the in-vessel components, and the vacuum system.

\subsection{Magnet system}

The magnet system comprises the 70 superconducting coils which are fed from power supplies via a sc bus system and current leads. The coils are supported with regard to weight and EM forces by a complex and highly loaded mechanical structure. The total cold mass is around 400 tons.

\subsubsection{Coils}

The NPCs and PLCs are composed of winding packs which are embedded within stainless steel casings. Each coil is supplied with electrical current and the supercritical He coolant via the header area. Details of the coil system and tests are given also elsewhere at this conference [9-12]

\subsubsection{Superconducting cables}

The cable-in-conduit superconductor for all coils was manufactured by a consortium of EAS and Luvata (formerly VAC and OCSI, Germany and Italy, resp.). It is composed of $243 \mathrm{Cu}$-stabilized NbTi strands, and a co-extruded Al-alloy jacket. The cable void fraction of $37 \% \pm 2 \%$ is used as channel for the $\approx 4 \mathrm{~K}$ supercritical $\mathrm{He}$ coolant. All WPs are built up from double-layers with conductor lengths ranging from $120 \mathrm{~m}$ to $180 \mathrm{~m}$. At the coil terminals the individual conductors are connected electrically in series with joints having resistances $<1 \mathrm{n} \Omega$. The He is supplied in parallel via filters (10 $\mu \mathrm{m}$ mesh size) and high voltage insulators to the joints.

As of now, all the conductors for coil and bus manufacturing including some spare have been produced and accepted.

\subsubsection{Non-planar coils (NPC)}

The NPCs are manufactured by a German-Italian consortium of Babcock Noell $\mathrm{GmbH}$ and Ansaldo Superconduttori. For each NPC, six lengths of fibre glass 
insulated cable are wound in double-layers with 18 turns each. The epoxy-impregnated WP is embedded in a cast steel casing, the embedding material is epoxyimpregnated quartz sand. The casing is made out of two half-shells which are welded together. Four reference pins on each side of the WP indicate its position within the casings. Measurements on winding packs show deviations from the CAD models of $<4 \mathrm{~mm}$ and deviations from the average shape of less than $2 \mathrm{~mm}$ [13]. A margin for assembly tolerances of about the same order, i.e. $2 \mathrm{~mm}$, is still available. The casings are machined at their support interfaces to an accuracy of $0.5 \mathrm{~mm}$.

The 316 LN steel cast casings (produced by Österby Gjuteri AB, Sweden) comprise wall reinforcements like ribs and gussets. Cast and on-welded blocks serve as interfaces to other coils and structure elements. These bulky cast spots are prone to imperfections; they are thus investigated employing hard x-rays from a linear accelerator, and repaired if necessary. Resulting from the refined FEA, some of the interface blocks had to be renewed or reinforced by stronger welds.

The coil casings are covered by on-welded $\mathrm{Cu}$ stripes that conduct incoming heat to the stainless steel cooling tubes. The latter are soft soldered to the stripes.

Fig. 2 shows a NPC of type 5 during pre-assembly. The Cu stripes with cooling pipes and the header facing downwards can clearly be seen.

Development of cable and coils required more time than anticipated. In addition, a series of quality problems, mainly in the termination areas, was discovered during the acceptance tests. These were poor quality welds, leaks, and in particular imperfections of the electrical insulation within the terminations. The insulation flaws were mainly discovered during high voltage tests under Paschen minimum conditions $\left(9.1 \mathrm{kV}_{\mathrm{dc}}\right)$ before and after the cryogenic tests at CEA in Saclay, France. Establishing repair procedures, repair, and repeated tests took much time and led to considerable delay of coil delivery. In addition, a serious damage of the test stand refrigerator caused another substantial delay, so that up to July 2006 only one coil could be assembled. Now most of the defective coils are repaired and waiting to be tested at the Saclay facilities where work has restarted again. 
The NPC production status is the following: 49 winding packs have been built, 25 coils are in different stages of fabrication, and 15 coils have been finished with most of them yet to be tested in Saclay.

\subsubsection{Planar coils (PLC)}

The PLCs are manufactured by Tesla comp., UK. The WP is made up of three double-layers with 12 windings each which are connected in series and parallel with regard to electrical current and He flow, respectively.

The casings consist of two rings each, constituting the walls parallel to the coil axis, and bolted top and bottom plates. The WPs are fixed by GRP wedges, the interstice is filled with resin-impregnated glass spheres. Cu plates cover each casing and transfer incoming heat to a circumferential stainless steel cooling tube which is soldered to the plates via Cu-blocks. The plates, with gaps in between to limit eddy currents, also serve as thermal radiation shield.

Refined FEA demonstrated the need for strengthening the casings by additional shear pins in the top and bottom plates. The pins were installed without causing much delay. Some quality problems were also discovered in the termination areas which required, amongst others, the replacement of the He-filters in front of the conductors.

As of July 2006 all WPs are ready, 11 are embedded in the casings, and three coils were accepted. Another four coils are waiting for the cryogenic tests in Saclay.

\subsubsection{Coil current supply}

\subsubsection{Busbar system}

Sc busbars (provided by Forschungszentrum Jülich, FZJ) with a total length of about $1100 \mathrm{~m}$ connect the coils with each other and the current leads. The same conductor as for the coils is employed. Routing for the group of 10 NPCs type 1 is bifilar in order to avoid error fields. All other groups are connected pairwise such that the current flows alternately in opposite directions around the torus.

The approx. 300 separable low-resistance joints for the busbars [14] experience in case of quenches pressures up to 170 bar. Hence thay are made from steel with Al- 
steel transition elements between the cable jackets and joint housings. The electrical insulation is consequently of the same quality as that of the coil terminations. The bus lines are monitored by a detection system which triggers a fast shutdown in case of a superconductor quench.

Design of the busbar system has been finished, and manufacture has started.

\subsubsection{Current leads}

The seven coil groups are each supplied by a current lead pair whose warm contacts are joined to the massive warm busbar system.

A distinctive feature of the current leads is their upside-down orientation, i.e. the cold ends are at top. This requires a suitable design of the heat exchanger which cools the central conductor. The current leads will use high temperature superconductors with a He inlet temperature of $\approx 50 \mathrm{~K}$. They are being developed and will be manufactured and tested by the Forschungszentrum Karlsruhe (FZK) and sub-contractors.

\subsubsection{Power supply and protection}

Seven units of twelve-pulse rectifier power supplies (max. $20 \mathrm{kA}$ and $30 \mathrm{~V}$ DC, accuracy $2 \times 10^{-3}$ ) were manufactured by the Swiss company ABB.

Fast discharge of the sc coils is realised by dumping most of the magnetic energy to variable resistors. The latter are made from totally $\approx 4.3 \mathrm{t}$ of pure nickel having high heat capacity and strong positive $\mathrm{d} \rho / \mathrm{dT}$ which simultaneously reduce switching voltages and discharge times [15].

The quench detection system is developed in co-operation with FZK [16]. It consists of nearly 400 units which permanently check the differential voltages across all coil double layers and busbar sectors. Signal amplifiers for millivolt signals which withstand the high voltages have already been successfully tested.

\subsubsection{Support structure}

In the last years, vast efforts were undertaken to create appropriate FEA tools for the support structure including coil casings [7]. Together with several European 
institutions and companies, global as well as detailed FE models were developed to simulate different load conditions and assembly procedures. As a result, the structure had in large parts to be re-worked and reinforced, final iterations are still ongoing. However, the system is converging so that from this side no major delays are expected any more, only some last design details are still open.

For increasing the safety margins concerning fatigue, and in particular for the inter-coil gliding elements, it is considered to decrease the total load cycle number from $\approx 4000$ to maximally 1000 by going from a daily to a weekly magnet shutdown operation scenario.

Further details of the support structure are given elsewhere at this conference [1720].

\subsubsection{Central support structure (CSS)}

The NPC and PLC will be fixed to the 72 ton central support ring which is manufactured by Equipos Nucleares S. A. (ENSA) in Spain. Following the machine symmetry, the CSS is composed of $10 \mathrm{HMs}$ made of steel plates with two cast extensions ("central support elements", CSE) for fixation of each coil. Long studs and sleeves from Inconel 718 under high pre-stress allow sufficient elastic deformation for keeping the stresses within coils and structure below allowed limits. Transversal and torsional forces as well as moments are supported by friction in the CSE flanges, and by welded wedges. A final test program is going on to qualify the delicate wedge welding procedure.

The CSS half-modules (Fig. 3) are machined with an accuracy of a tenth of a millimetre (by the sub-contractor Rovera, Italy). They will be bolted together with an exact fit at the HM interfaces, and with custom-made shim plates at the module connections for final adjustment.

Manufacture of the CSS has experienced some delay as the continuous refinement of structural FEA resulted in design modifications. In addition, technical problems with surface cracks in the cast extensions required further R\&D and repair. The first HM of the support ring is scheduled for delivery in autumn 2006. 
Ten cylindrical pillars carry the support structure, and their GRP parts provide the thermal barrier between the cold magnet system and the machine base at ambient temperature.

\subsubsection{Inter-coil supports}

Originally a soft structure was favoured resulting in large excursions of the coils while still maintaining the symmetry. However, comprehensive studies revealed excessive stresses and required re-engineering at a relatively late stage.

Narrow support elements (NSE) are arranged along the inboard side of adjacent coils. They are exposed to loads of up to $1.1 \mathrm{MN}$ and have to allow up to $8 \mathrm{~mm}$ gliding and up to $1^{\circ}$ tilting of the coils against each other. A comprehensive R\&D programme was established to investigate friction and stick-slip effects under relevant loads at cryogenic temperatures. Following these tests, Al-bronze pads with $\mathrm{MoS}_{2}$ PVD coating were chosen. The pads are kept by pad holders which in turn are shrink-fitted into the coil casings. The counter-sides are sprayed with a $\mathrm{MoS}_{2}$ spray (ROCOL ${ }^{\circledR}$ Oxylube) or burnished with $\mathrm{MoS}_{2}$ powder using a specially developed tool. In vacuum and $77 \mathrm{~K}$ this arrangement withstands with some statistical variation close to 4000 cycles under loads up to $1.5 \mathrm{MN}$ without significant friction factor deterioration or stick slip. Even though no changes are expected by going to $4 \mathrm{~K}$, corresponding tests are planned for confirmation.

The PLCs are supported - in addition to the CSE fixations - by the NPCs via four "planar support elements" each. Two alternative designs are being developed in parallel. One of them is based on gliding elements similar to the NSEs, the second and favoured design consists of bolted elastic connections. The final choice will be taken in late summer 2006.

Lateral support elements (LSE) connect the coils along the outboard side of the torus and form a "helical belt". All LSEs within the HMs are welded, corresponding trials were performed by FZJ to assess shrinkages in order to compensate for the distortions of the magnet. The interface between adjacent half-modules is composed 
of special LSEs (one bolted and one welded) and additional "contact elements" which again are based on sliding pads.

\subsection{Cryostat}

Most of the cryostat main components, the plasma and outer vessels as well as the thermal insulation, are manufactured by the German company MAN DWE, and the Swiss company Romabau Gerinox fabricates the ports.

Apart from the description below, further details of the cryostat are given in separate presentations at this conference [21-23].

\subsubsection{Plasma vessel (PV)}

The plasma vessel is composed of ten half-modules which are divided into two sectors each to allow string-on of the innermost NPC (type 3). The vessel is built up from bent and welded steel rings with an accuracy from $3 \mathrm{~mm}$ to $7 \mathrm{~mm}$, with the closest tolerances at the inboard side. Water pipes welded around the outer PV wall allow temperature control, and serve also as heaters for bake-out at $150{ }^{\circ} \mathrm{C}$. Manufacture of all the 20 sectors has been completed in 2005.

Fig. 4 shows one PV sector with water cooling pipes (right side) and part of the thermal insulation (s. below). Well visible is the aluminized surface of the thermal shield with $\mathrm{Cu}$-braids for heat transfer from the shield to the He cooling pipes. The latter are mounted after connecting both PV sectors to a HM. The multi-layer insulation is below the shield.

Rogowski and saddle coils for magnetic diagnostics are mounted directly onto the outside of the vessel sectors during assembly preparation. The thermal insulation on the PV is assembled hand in hand with stringing-on the coils.

\subsubsection{Outer vessel (OV)}

The OV is assembled from module half-shells. It will have 549 openings (without secondary openings in flanges, domes, etc.) for ports, supply lines, PV access ports, and current as well as instrumentation feedthroughs. All half-shells have been 
manufactured; for about half of them all holes are cut, and for the first module all domes and port flanges are welded (except those planned to be installed on site).

\subsubsection{Ports}

W7-X will be equipped with 299 ports of different shapes and dimensions (up to $0.4 \times 1 \mathrm{~m}^{2}$ for rectangular ports). 160 will be used for plasma diagnostics, 19 for heating systems, 20 for pumping, and 100 for supply of IVCs. Bellows compensate for deformations and displacements of the PV with respect to the OV. The bellows of the 100 supply ports are mounted between the rigid port cylinders and the OV, whereas the bellows of the remaining ports are integral parts of their walls. Water pipes are attached to the port walls via copper stripes for temperature control. 275 port assemblies including bellows, water pipes, flanges, and instrumentation are accepted and delivered already.

\subsubsection{Thermal insulation}

Protection of the cold components against gas heat conduction and thermal radiation is achieved by high vacuum, actively cooled radiation shields, and 20 layers of reflecting foils between the shields and warm cryostat walls. For the shields a novel technique was developed, applying epoxy impregnated glass fibre panels with integrated copper meshes [24]. The latter provide good thermal conductivity and are intersected to reduce eddy currents. The shields are kept at $40 \mathrm{~K}$ to $70 \mathrm{~K}$ by helium flowing through tubes which are attached by copper braids. Sixteen panels, this is the maximum possible before continuation of coil assembly, have been mounted within specified tolerances $( \pm 2 \mathrm{~mm})$ on the first $\mathrm{HM}$ of the PV.

The shields of ports and OV are generally of copper, in high field regions at the ports near the PV they are of brass in order to reduce eddy currents during fast coil discharges. The OV shield panels (16 per module) are cooled by He-pipes which are attached via $\mathrm{Cu}$-blocks, whereas the port shields are cooled by heat conduction to the PV and OV shields. Design of the OV and port shields has well progressed, component prototypes are being built, and assembly tests are underway. The insulation technologies for the next components to be installed are ready in due time. 


\subsection{In-vessel components (IVC)}

Power and particle exhaust are mainly diverted to target plates which are the core components of the divertor units, one on top and one on bottom of each module. The full system of IVCs comprise also the baffles which border on the target plates and reduce back-flow of neutrals to the plasma, the PV wall panels and heat shields, the control coils to modify the magnetic configuration at the plasma boundary, the cryopumps to remove neutral gas during high-density plasma operation, and the corresponding water, $\mathrm{LN}_{2}$ and supercritical He supply lines.

This system is designed for steady-state operation at heating powers of $10 \mathrm{MW}$ ECRH and additional 10 s pulses of ultimately 20 MW NBI and 4 MW ICRH. The exhaust energy is mainly transferred to the target plates which experience high power fluxes of up to $10 \mathrm{MW} / \mathrm{m}^{2}$, but partly also to the baffles which are exposed to fluxes up to $0.5 \mathrm{MW} / \mathrm{m}^{2}$, and to the wall protection. The latter is subjected to power fluxes of maximally $0.3 \mathrm{MW} / \mathrm{m}^{2}$.

\subsubsection{Target plates}

Fig. 5 shows a CAD drawing of a target module having a plasma facing surface of $\approx 2 \mathrm{~m}^{2}$ which is composed of tiles. The final module is machined to achieve smooth surfaces without leading edges.

The tiles consist of 6 - $8 \mathrm{~mm}$ thick carbon-fibre-composite (CFC) from Snecma, France. They are bonded by active metal casting to $\mathrm{Cu}$ which in turn is joined to water-cooled $\mathrm{CuCrZr}$ heat sinks either by electron beam welding or hot isostatic pressing (final procedure not yet determined). The cooling channels are equipped with swirl-tubes to enhance heat exchange.

The first tile series showed lower tensile strength than specified, but the material can still be used for the target elements which are being manufactured by Plansee comp., Austria. First prototype tests withstood loads up to $12 \mathrm{MW} / \mathrm{m}^{2}$ in the GLADIS facility at IPP Garching but developed some cracks at the interface between the CFC tiles and the heat sink [25]. Plansee has proposed adequate design changes and will deliver improved prototype elements in autumn. 
The middle region $\left(0.56 \mathrm{~m}^{2}\right)$ of the horizontal target plates has to withstand only power loads up to $1 \mathrm{MW} / \mathrm{m}^{2}$. There the same technology is used as for the baffle plates (see below). Module fabrication and testing will be done by IPP Garching.

\subsubsection{Baffles}

As these plates are less loaded, they can be simpler manufactured from $10 \mathrm{~mm}$ thick fine grain graphite elements clamped to water-cooled $\mathrm{CuCrZr}$ alloy heat sinks. The baffle modules cover an area of about $30 \mathrm{~m}^{2}$ and are fabricated in the workshops of IPP Garching.

\subsubsection{Wall protection}

About $65 \mathrm{~m}^{2}$ of the outboard plasma vessel surface will be covered by watercooled double-walled stainless steel panels. The panels are being manufactured by MAN DWE.

In areas where the plasma is close to the wall, i.e. mostly on the inboard side of the torus (in total $\approx 30 \mathrm{~m}^{2}$ ), the same technology as with the baffles will be applied.

\subsubsection{Control coils}

Ten control coils behind the baffle plates will be used to correct small field errors at the plasma edge, to optimize position and extent of the magnetic islands, and to dynamically sweep and distribute the power across the target plates.

The coils are wound from a hollow $\mathrm{Cu}$ conductor and cooled by water. Production has started at Babcock Noell, and the first exemplar will be delivered in summer 2006.

Each coil will be supplied by its own power supply with a DC current of $2.5 \mathrm{kA}$. An ac sweeping component from zero to $0.625 \mathrm{kA}$ with frequencies up to $20 \mathrm{~Hz}$ can be superimposed. The corresponding terminal peak voltage is $30 \mathrm{~V}$.

The power supplies have been delivered by the Spanish company JEMA [26]. 


\subsection{Vacuum system}

\subsubsection{Plasma vessel vacuum}

Turbomolecular pumps (TMP) with roots and rotary forepumps, having together an effective capacity of $\approx 25 \mathrm{~m}^{3} / \mathrm{s}$, evacuate the plasma vessel and exhaust neutrals from the divertor region. The sensitivity of the TMP rotors to magnetic stray fields compels adequate positioning about $4 \mathrm{~m}$ away from the torus surface.

Behind the baffles, cryo-pumps will be installed which can be operated at temperatures down to $3.4 \mathrm{~K}$, giving a total additional pumping capacity of $\approx 75 \mathrm{~m}^{3} / \mathrm{s}$ for hydrogen and deuterium during high-density plasma operation. They are composed of He-cooled cryo-panels, and are shielded against thermal radiation by $\mathrm{LN}_{2}$-cooled Chevron baffles and reflectors. Additional water-cooled Chevrons protect against plasma radiation. All components are manufactured by IPP Garching.

\subsubsection{Cryostat vacuum}

The cryostat has a volume of $\approx 500 \mathrm{~m}^{3}$ and is designed for a vacuum of $10^{-5} \mathrm{mbar}$ at a maximal He leak rate of $10^{-2} \mathrm{mbar} \cdot 1 / \mathrm{s}$. Planned evacuation time before start of cool-down is 72 hours. Due to magnetic stray fields the TMPs have to be attached to the OV flanges via $\approx 4 \mathrm{~m}$ long straight tubes (i.D. $320 \mathrm{~mm}$ ). These conditions are fulfilled by 5 pumping units, each one with a 2000 1/s TMP and a $65 \mathrm{~m}^{3} / \mathrm{h}$ rotary vane pump. For pump down, and as a stationary operation back-up, two additional roots pumps and rotary vane pumps will be installed.

\section{W7-X Assembly}

Assembly of Wendelstein 7-X is quite sophisticated and requires high precision during all steps $[27,28]$. Appropriate tools and technologies have been and are being developed, and personnel is being trained continuously. Coil stringing has been simulated with interactive CAD-models for collision checks and guidance during assembly. Some coils were temporarily sent from the manufacturer to the W7-X site for full scale pre-assembly tests. FEA have been performed to predict and correct 
deformations of the mechanical structure as well as weld shrinkage during all assembly steps.

As the first major assembly step, the coils are strung over one HM of the PV, whereby the middle NPC can only be shifted over one of two PV parts which have to be joined thereafter. The thermal insulation, NSEs and LSEs are being mounted hand in hand with the coils. As the space between the thermally insulated PV and the NPCs, as well as among the coils themselves, is very limited, special handling tools have been developed that allow to move and rotate the coils with a precision of $1.5 \mathrm{~mm}$. When all seven coils are aligned, they are fixed to a half-module of the CSS with an accuracy of around 0.5 millimeter. This first assembly step is performed simultaneously in two mounting stands of type I which are adapted to the flipsymmetrical half-modules. Fig. 2 shows a NPC of type 5 and a PLC during preassembly on top of the PV (the other pre-assembled coils are not visible).

In mounting stand II both half-modules are connected, i.e. the LSEs between both coils of type 1 as well as the PV parts are welded, and the CSS half-modules are bolted together. Then the He cooling and busbar systems are assembled and leak tested, including the joints between individual busbar conductors. FZJ determined the collision-free assembly sequence for the 25 individual conductors per module.

Mounting stand III is mobile for transporting the magnet module to the torus hall. Some completion work, in particular instrumentation and cabling, will be performed there.

In mounting stand IVa the module is installed within the OV lower half shell which was already equipped before with thermal insulation. The whole component group is then moved to the final mounting stand IV which is a heavy structure linked to the machine base itself. There the module is closed with the OV insulated upper half-shell. About 60 ports and part of the in-vessel components are then installed, and some IVCs are pre-assembled. Port installation requires separate precise holding and alignment devices. 
Once the first three modules are individually assembled,they are adjusted at their final positions on the machine base (mounting stand $\mathrm{V}$ ) within $\pm 5 \mathrm{~mm}$ in order to minimize magnetic field errors. Shim plates are used to close the adjustment gaps between the CSS modules. Then the plasma and outer vessel modules are welded together, the remaining ports at the module interfaces are assembled, and the thermal insulation is completed. Partly in parallel, the remaining two modules are added in the same way.

As soon as the modules are finally positioned, assembly of periphery systems - as diagnostics, heating systems, water, cryo and electrical supply - can start on the central platform. The final assembly and adjustment of the in-vessel components will be done after closing the torus.

During all assembly steps a rigorous quality control has to be performed. Particular attention will be paid to leak tests of all assembly welds. For the coolant pipes this can be done in most cases at $\mathrm{LN}_{2}$-temperature by local cooling of the orbital welds.

After considerable delay there is now confidence that assembly can continue in a good pace in September 2006. Apart from the coils, all the initially needed tools, mounting stands, assembly technologies, and the personnel are ready. In order to minimise the delays, accelerating measures are investigated. Main action would be to install at a nearby industrial site a second assembly line in parallel up to mounting stand III.

\section{Summary and outlook}

An overview is given on the current status of W7-X component construction and assembly. It can be stated that component final design and manufacture generally progresses well, and the situation concerning the coils and mechanical structure is under control.

Following negative coil acceptance test results, in-depth analyses of the quality problems were performed which resulted in some detail re-design, repair, and 
manufacture process changes. Series production has resumed, and a number of finished coils is waiting to be tested under operation condition in Saclay. Due to the enforced schedule changes the cryogenic tests may well become a bottleneck, and it is planned to use an additional test bed in order to minimize the project risks, especially with regard to delays.

Concerning the highly loaded mechanical structure, the iterative process encompassing FE analyses, detail design, and development is converging to a stable system, and series production of structure elements are not hampered any more.

After removing the main causes of trouble there is confidence that machine assembly can be resumed with good pace this autumn. Part of the meanwhile accumulated delays could be compensated by accelerating measures in the device assembly.

\section{References}

[1] J. Nührenberg, W. Lotz, P. Merkel, C. Nührenberg, U. Schwenn, E. Strumberger and T. Hayashi., "Overview on Wendelstein 7-X Theory," Trans. Fusion Techn., vol. 27, pp. 71-78 1995

[2] D. Hartmann, C. Damiani, U. Neuner, et al., Wendelstein 7-X Torus Hall Layout and System Integration, $24^{\text {th }}$ Symposium on Fusion Technology, 11-15 Sept. 2006, Warsaw, Poland, Paper P1-A-436

[3] J. Schacht, H. Laqua, A. Spring, et al., Overview and status of the system control of Wendelstein 7-X, $24^{\text {th }}$ Symposium on Fusion Technology, 11-15 Sept. 2006, Warsaw, Poland, Paper P2-C133

[4] H. Laqua, J. Schacht, A. Spring, et al., Runtime resource checking at WENDELSTEIN 7-X during plasma operation, $24^{\text {th }}$ Symposium on Fusion Technology, 11-15 Sept. 2006, Warsaw, Poland, Paper P2-C-117

[5] A. Spring, J. Schacht, H. Laqua, et al., User Control Interface for W7-X Plasma Operation, $24^{\text {th }}$ Symposium on Fusion Technology, 11-15 Sept. 2006, Warsaw, Poland, Paper P2-C-153

[6] H. Braune, P. Brand, V. Erckmann, et al., Architecture of central control system for the $10 \mathrm{MW}$ ECRH-plant at W7-X, 24 ${ }^{\text {th }}$ Symposium on Fusion Technology, 11-15 Sept. 2006, Warsaw, Poland, Paper P3-B-134

[7] V. Bykov, F. Schauer, K. Egorov, et al., Structural Analysis of W7-X: Main Results and Critical Issues, $24^{\text {th }}$ Symposium on Fusion Technology, 11-15 Sept. 2006, Warsaw, Poland, Paper P1-E369

[8] J.H. Feist, H.-J. Bramow, R. Brockmann, et al., Quality Management for WENDELSTEIN 7-X Lessons learned, $24^{\text {th }}$ Symposium on Fusion Technology, 11-15 Sept. 2006, Warsaw, Poland, Paper P3-J-397

[9] B. Petersen-Zarling, H. Ehmler, D. Gustke, et al., Experience with High Voltage Tests of the W7-X Magnets in Pachen-Minimum Conditions, $24^{\text {th }}$ Symposium on Fusion Technology, 11-15 Sept. 2006, Warsaw, Poland, Paper P1-E-25 
[10] M. Schröder, J. Holluba, K. Heyn, et al., Quality assurance of aluminium weld seams and cast casings of the W7-X coils, $24^{\text {th }}$ Symposium on Fusion Technology, 11-15 Sept. 2006, Warsaw, Poland, Paper P1-E-353

[11] M. Wanner, C. Sborchia, K. Riße, et al., Experience gained during Manufacture and Testing of the W7-X Superconducting Magnets, $24^{\text {th }}$ Symposium on Fusion Technology, 11-15 Sept. 2006, Warsaw, Poland, Paper O3B-E-64

[12] H. Ehmler, J. Baldzuhn, L. Guerrini, et al., Review of the Factory Acceptance Tests and Cold Tests of the W7-X Superconducting Magnets, $24^{\text {th }}$ Symposium on Fusion Technology, 11-15 Sept. 2006, Warsaw, Poland, Paper P1-E-36

[13] T. Andreeva, J. Kisslinger, Validation of Wendelstein 7-X Fabrication and Assembly Stages by Magnetic Field Calculations, Fusion Science and Technology, Vol. 50 (2006) 258 - 261

[14] K. Rummel, M. Czerwinski, F. Hurd, et al., Test Results from Full Size Prototype Test of W7-X Joint, $24^{\text {th }}$ Symposium on Fusion Technology, 11-15 Sept. 2006, Warsaw, Poland, Paper P1-E346

[15] M. Köppen, J. Kißlinger, Simulation of Voltage and Current Development in the Wendelstein 7-X Coil System Taking into Account Fault Conditions, $24^{\text {th }}$ Symposium on Fusion Technology, 11-15 Sept. 2006, Warsaw, Poland, Paper P1-E-422

[16] D. Birus, Th. Rummel, M. Fricke, et al., Development of Quench Detections for W7-X, $24^{\text {th }}$ Symposium on Fusion Technology, 11-15 Sept. 2006, Warsaw, Poland, Paper P1-E-35

[17] C. Damiani, A. Benndorf, V. Bykov, et al., Design and development of the Wendelstein 7-X inter-coil supports: main results and critical issues, $24^{\text {th }}$ Symposium on Fusion Technology, 1115 Sept. 2006, Warsaw, Poland, Paper P1-E-281

[18] K. Egorov, Detailed Structural Analysis of critical Wendelstein W-7X magnet system components, $24^{\text {th }}$ Symposium on Fusion Technology, 11-15 Sept. 2006, Warsaw, Poland, Paper P1-E-452

[19] D. Pilopp, A. Cardella, A. Ruiz, et al., Manufacture of the Central Support Structure for WENDELSTEIN 7-X, $24^{\text {th }}$ Symposium on Fusion Technology, 11-15 Sept. 2006, Warsaw, Poland, Paper P1-E-41

[20] A. Dudek, A. Benndorf, V. Bykov, et al., Tests of the Critical Bolted Connections of the WENDELSTEIN 7-X coils, $24^{\text {th }}$ Symposium on Fusion Technology, 11-15 Sept. 2006, Warsaw, Poland, Paper P1-E-298

[21] A. Cardella, B. Hein, D. Hermann, et al., Construction of the Vacuum Vessels and the Magnet Supporting Structures of WENDELSTEIN 7-X, 24 ${ }^{\text {th }}$ Symposium on Fusion Technology, 11-15 Sept. 2006, Warsaw, Poland, Paper O4B-G-149

[22] T. Koppe, A. Cardella, B. Missal, et al., Vertical supports of the plasma vessel Wendelstein 7-X, $24^{\text {th }}$ Symposium on Fusion Technology, 11-15 Sept. 2006, Warsaw, Poland, Paper P2-G-57

[23] J. Reich, A. Cardella, A. Capriccioli, et al., Experimental verification of the axial and lateral stiffness of large W7-X rectangular bellows, $24^{\text {th }}$ Symposium on Fusion Technology, 11-15 Sept. 2006, Warsaw, Poland, Paper P2-G-39

[24] F. Schauer, M. Nagel, Y. Bozhko, et al, thermal Insulation of the Wendelstein 7-X superconducting magnet system, Proc. $20^{\text {th }}$ Int. Cryog. Eng. Conf. (ICEC 20) Beijing, China (2005) 853 - 856

[25] J. Boscary, H. Greuner, K. Scheiber, et al., Results of the examinations of the W7-X pre-series target elements, $24^{\text {th }}$ Symposium on Fusion Technology, 11-15 Sept. 2006, Warsaw, Poland, Paper P2-F-37

[26] F. Füllenbach, Th. Rummel, S. Pingel, et al., Final Test of the W7-X Control Coils Power Supply and its Integration into the overall Control Environment, $24^{\text {th }}$ Symposium on Fusion Technology, 11-15 Sept. 2006, Warsaw, Poland, Paper P1-E-22

[27] T. Bräuer, Metrology of W7-X - Results of first Component Adjustment, $24^{\text {th }}$ Symposium on Fusion Technology, 11-15 Sept. 2006, Warsaw, Poland, Paper P1-A-357

[28] L. Wegener, Wendelstein 7-X at the transition to assembly, Fusion Engineering and Design 74 (2005) 41-48 
Figures

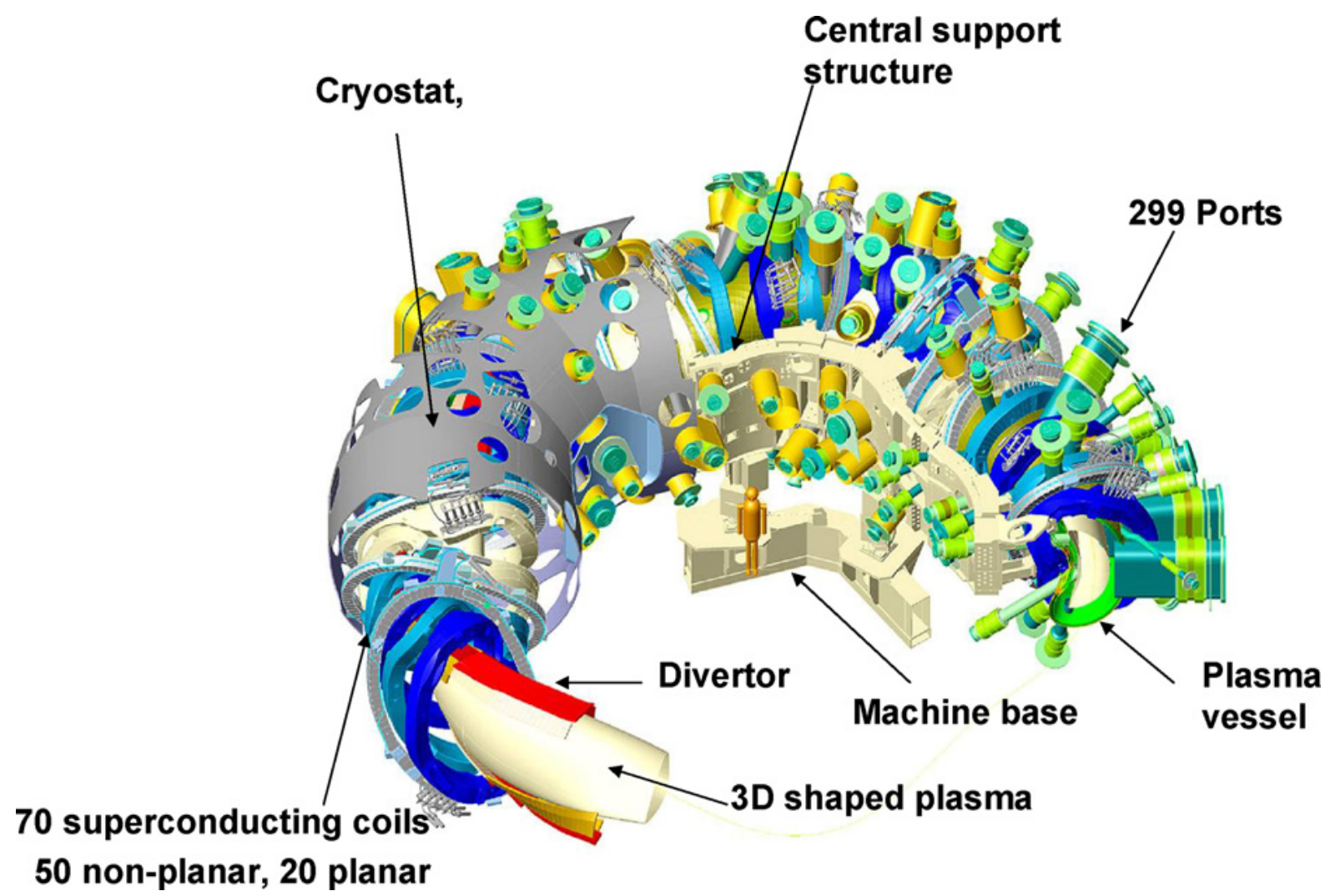

Fig. 1. CAD drawing of the W7-X basic machine 


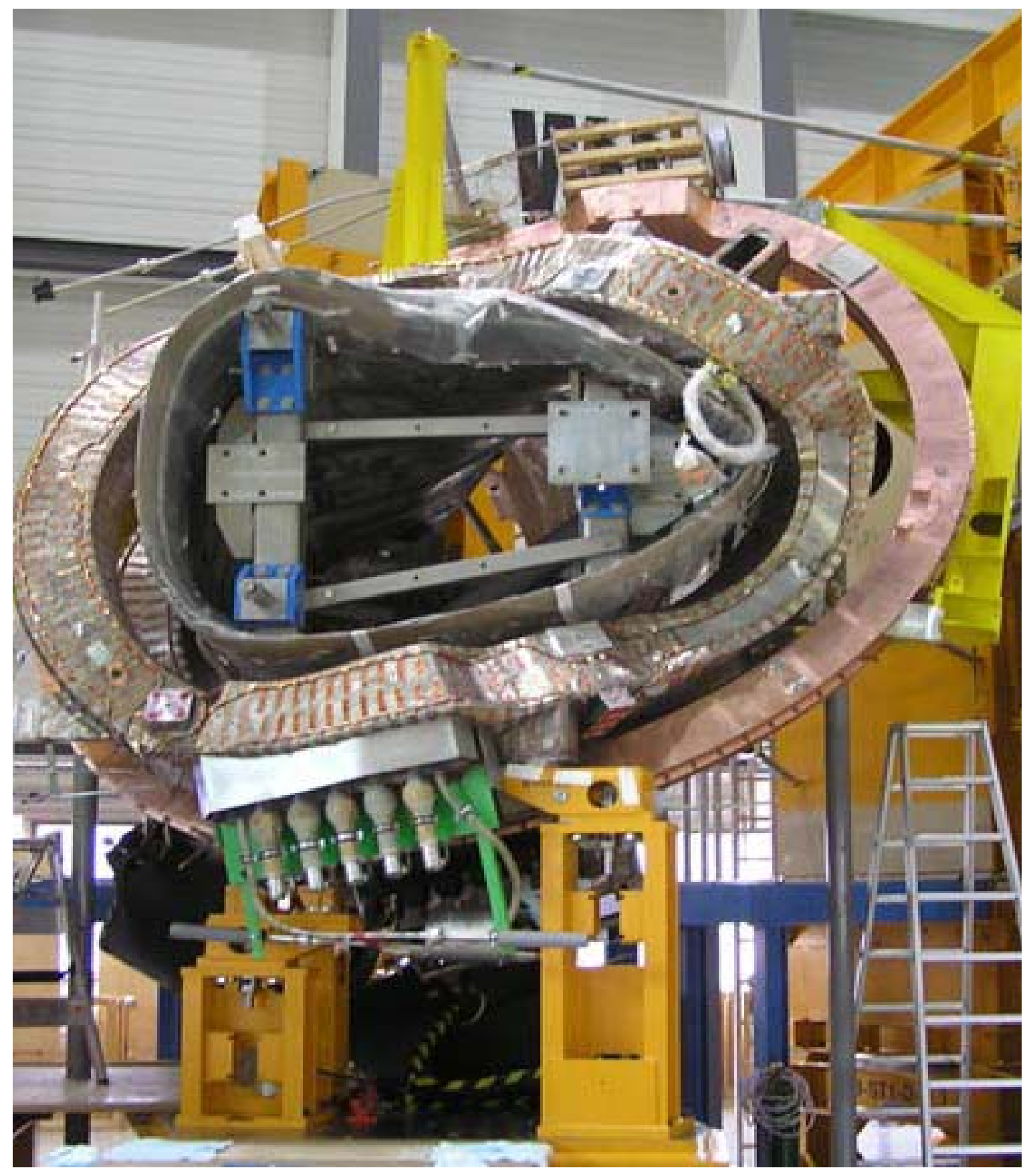

Fig. 2. Non-planar coil type 5 and planar coil during pre-assembly 


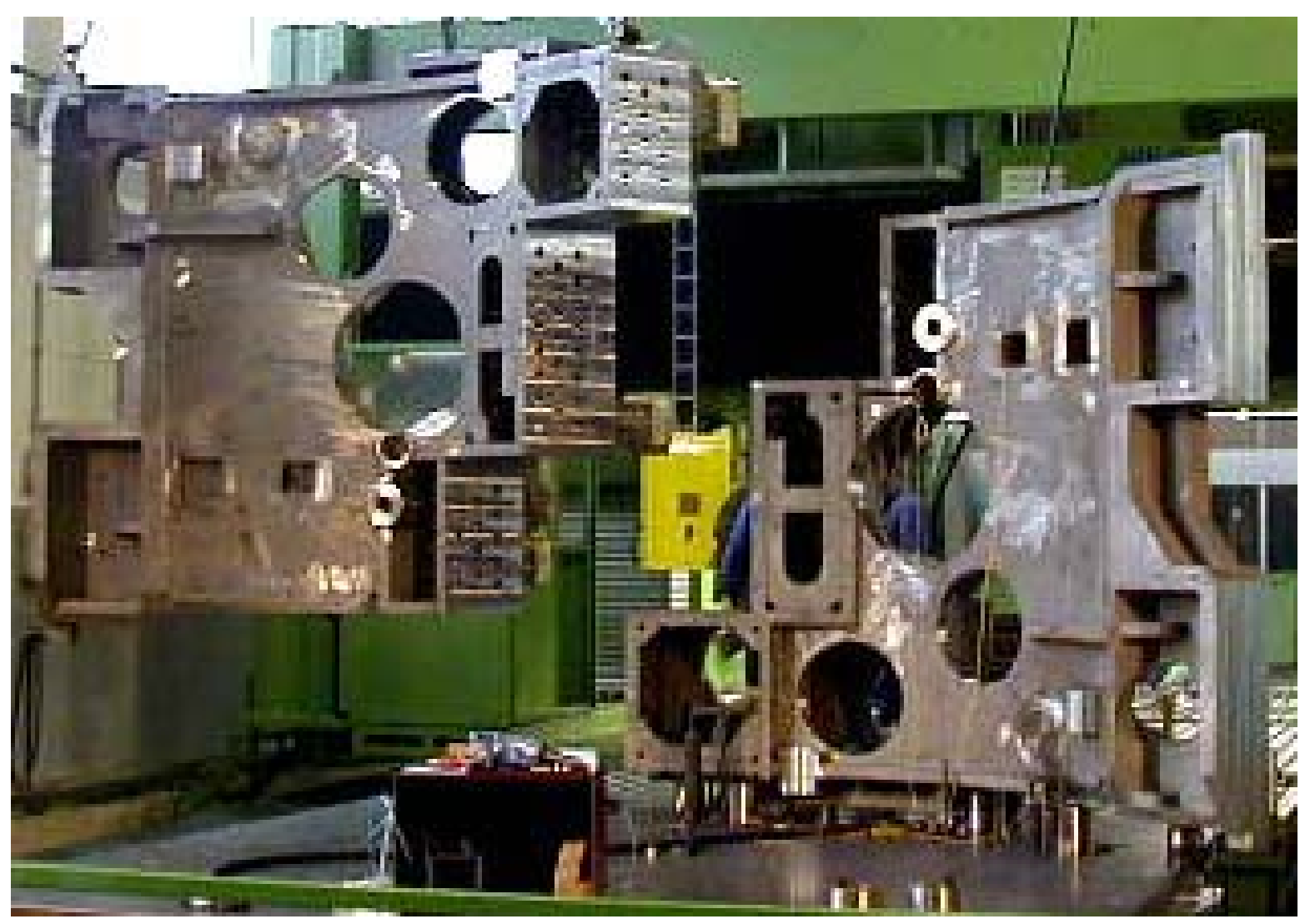

Fig. 3. Two half-modules of the central support structure 


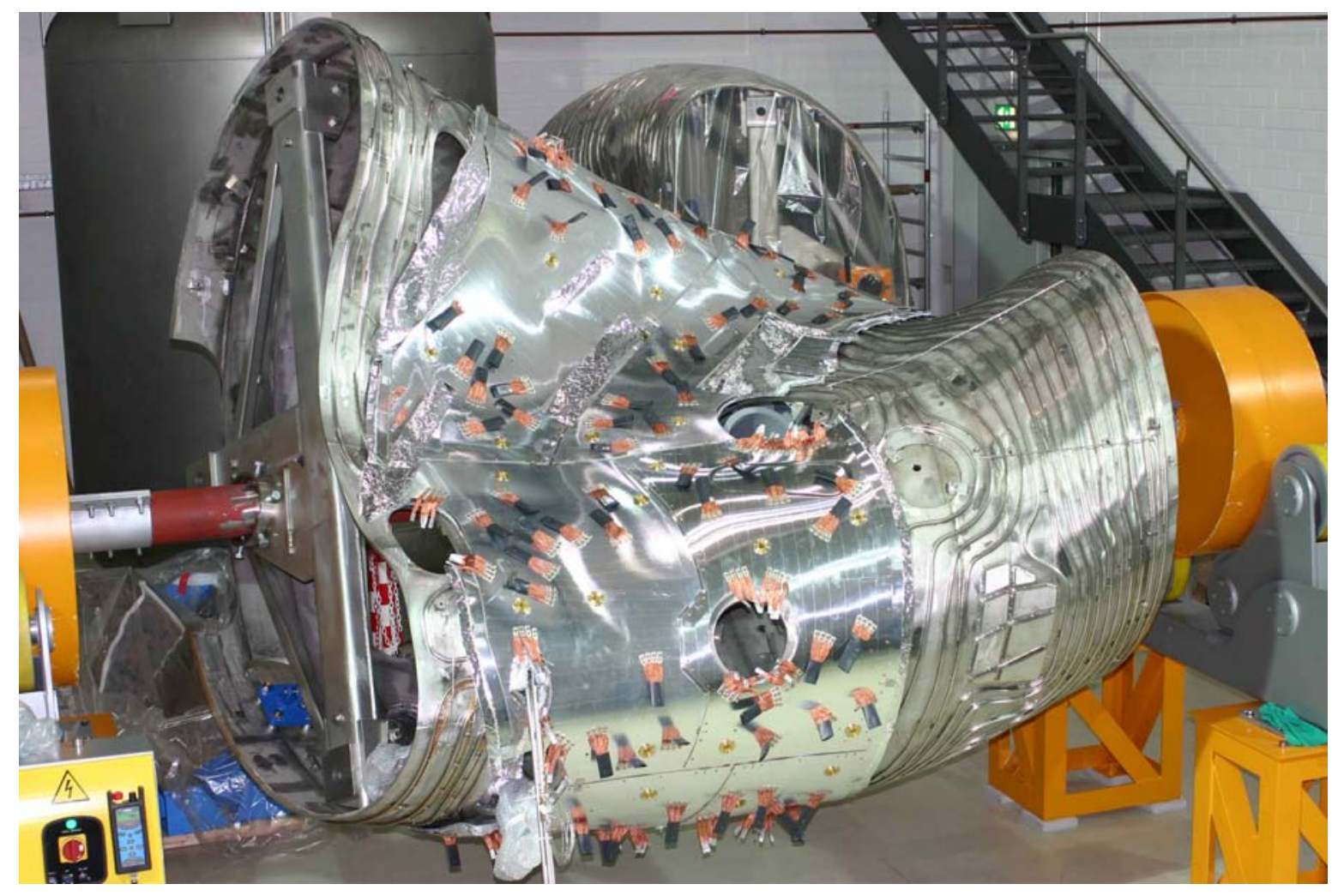

Fig. 4. Plasma vessel sector with insulation below coil type 3 position (left) and vessel water cooling pipes (right) 


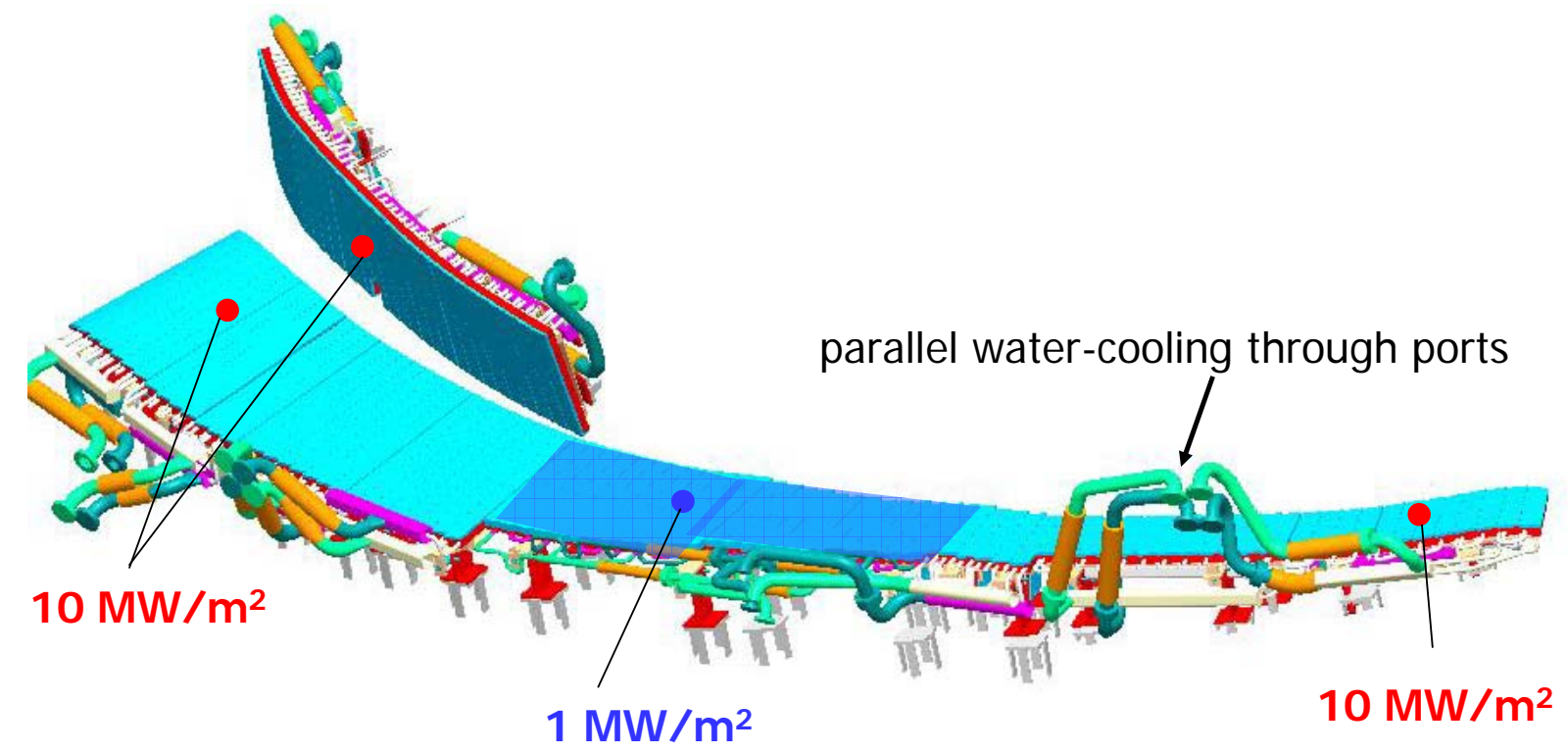

Fig. 5. CAD model of divertor target module 